\title{
Back to the Drawing Board Inventing a Sociology of Technology
}

\author{
Cornelis Disco
}

\section{Introduction}

One of the great lapses of the sociological imagination has surely been an appreciation of the role of technology in society. The "founding fathers" - if we may except Marx - paid it scant attention, and their intellectual descendents have done little better. Mark Shields says:

\footnotetext{
The vital sociological traditions of theorising about phenomena such as the state, power, social class, ideology, division of labour, religion, revolution ... have barely touched technology. This is a stunning omission. Shields 1997, 188)
}

What is stunning is of course the lack of interest in a phenomenon which by all accounts has been one of the prime levers of change in modern societies. The classical mission of sociology, to offer a new reflexive self-understanding for post-feudal, industrial societies, would seem to encourage sociologists to position the study of technology at the very centre of their intellectual programme. Instead, they have marginalised and disdained technology, treating it as a trivial corollary of economic or scientific rationality, and of sociological relevance only insofar as it had effects on other societal patterns (Ogburn 1922; Gouldner and Peterson 1962). Technology has been taken seriously as a sociological phenomenon itself by only a very few sociologists (Gilfillan 1935; Noble 1984). For the most part, it has been left to renegade traditions like Marxism and labour-process theory (MacKenzie 1984), recently reinforced by the new social studies of technology ( nology and reposition it as an authentic societal phenomenon. However, these traditions have adopted more or less sectarian standpoints with respect to mainstream sociology and have reinforced, rather than weakened, sociological prejudices regarding the ontological and epistemological "otherness" of technology. ${ }^{1}$ 
This is not the place to dwell on the many reasons for the suppression of technology in the sociological project. What we can do here is examine how, given the nature of technology and the deep structure of academic sociology, technology might be incorporated into the sociological program in a way commensurate with its societal importance.

As to the nature of technology, it is now clear that it is far from the straightforward means (or set of tools) that sociologists have generally taken it to be. We shall have occasion to dwell on this point in connection with four "technological parables" in the following section. As to the "deep structure" of sociology, I take that to refer to the essential opposition between (or dialectic of) agency and structure which has been the primal matrix of social theory from the times of Adam Smith, Karl Marx, Emile Durkheim, and Max Weber onwards. In its classical form, this dialectic posits a mutually constitutive relationship between individual human beings (or social groups) and a larger social collectivity. It is a compact way of accounting for, on the one hand, social order and stability (i.e., the Hobbesian problem of how numerous individuals, often at cross-purposes, can maintain stable patterns of interaction) and, on the other, social change (how those stable patterns can evolve or even be dramatically transformed). The scheme expresses a relation between situated social action (agency) and an order of sedimented norms, role expectations, laws and ... technologies (structure). The relation is such that social action is shaped and given meaning by these sedimented structures, but also that social action in turn impinges on social structure, either reinforcing it or causing it to change: i.e., to evoke new patterns of interaction and new sedimentented structures.

Traditionally, this scheme has tended to apportion different types of entities to the poles of agency and structure, respectively. Humans, defined as uniquely endowed with consciousness and intentionality, have been seen as the primary, if not the only, sources of social agency. Non-human entities, e.g., texts, beliefs, and material objects and systems, have been apportioned to the sphere of structure. Technology thus becomes a feature of the sociological landscape rather than an actor on the historical stage. The scheme has also defined human beings as the sole makers of society. Bruno Latour has attacked this "modernist purification" with vigour and imagination (Latour 1990, 2002). For him and others, it has been sufficient reason to reject the sociological tradition tout court and to turn to one other metaphysics of the social. One may ask to what extent this is necessary or helpful. This depends on the answers to three additional questions: Is there good reason to challenge the traditional attribution of entities to the categories of "agent" and "structure"? Would such a re-attribution violate the logic of the dialectic or impair 
its sociological work? Is the dialectic of agency and structure the right centerpiece for a science of society; i.e., would the conceptual work of re-attribution be worth it? Is sociology worth saving for technology? Given what the field of Science and Technology Studies has revealed about technology over the past thirty years, it is clear that the answer to the first question must be "yes". The "technology parables" to be presented below merely confirm this. I will argue that the dialectic of agency and structure is not essentially implicated in any a priori ontological distinction between humans and nonhumans. It can work as a formal and methodological scheme quite apart from the contingent attributions of types of entities to one or another of the poles. Finally, in regard to the question of whether sociology is worth the effort of manipulating its DNA, I suggest it can be done; I also think it should be done, if only because sociology's foundational agency-structure dialectic is still the only approach which incorporates elements of psychology, economics, and history into a unified metaphysics of social action. Sociology provides the only potentially unified approach to modernity as an achievement (or catastrophe) leaving traces in time. It is worth having a world in which one can have one's nonhuman actors and eat the cake of sociology, too.

\section{Technologies}

To address this issue, it will help to have a concrete image of what we are talking about. Following are four stories about material artifacts, i.e., constructs intelligently designed to perform some specific function or task (whether or not they are held to do so in practice).

\section{Palm organizer}

Imagine having your daily schedule, important phone numbers, lists, meeting times and more in one organized place. It's easy and more affordable than ever with the Palm ${ }^{\mathrm{TM}}$ IIIe handheld. - advertisement for Palm. (www.palm.com)

Up front, advertisements for electronic organisers like the Palm series produced by $3 \mathrm{com}$ Inc. portray the new gadgets as productivity enhancers, as tools for organising fragmented lives. The Palm lets us apportion our time in advance. Its literal electronic memory "backs up" our own spotty faculties and infallibly reminds us of what we are to do and when we are to do it. At the same time, the volatility of electronic memory, the ease with which informa- 
tion can be erased, edited, and replaced makes it a highly flexible tool for time, task, and contact management.

Palm Inc. maintains a website including, among other things, a collection of customer testimonials. ${ }^{2}$ These reveal that Palm organizers enhance the capabilities of users, but also change their relationships to themselves and others. The testimonial writers invariably experience this as a positive change and consequently tend to fawn over their new "digital pals".

\section{USER 1}

I am a female sales professional working 50-60 hours while at the same time trying to manage a home, 2 small children, a marriage, etc. I live to be organised but sometimes have trouble keeping it all together. I ...charged it and began to enter data. Within hours, I had entered my year 2000 appointments, approximately 75 important dates (birthdays, etc), my children's school calendars, before- and after-school activities, not to mention several customised "to do" lists (daily, weekly, monthly, annually, biannually, etc). Needless to say, I have fallen in love with it... Thank you, Palm Computing, for making organisation so much fun!!!

\section{USER 2}

I work in the internet financial services industry and as such have to manage multiple and diverse projects, initiatives and issues. I am always on the move, in meetings or visiting outside the bank. Information is critical to ensure that details are not missed and that I can speak intelligently about the issues. There is invariably insufficient time to prepare, so having the information at my finger tips just as I last saw it on my laptop is absolutely critical for me.

Here is why my Palm V organiser is now a critical part of my life.

1 It fits in my pocket... I always have it with me.

2 Easy-Sync: I HotSync with Lotus Notes R5 and individuals across the Bank can view my schedule. I have a custom folder in Notes where my daily news from Slate and CNN are placed by a Lotus Notes "rule". I then HotSync that folder with the Palm V organiser and can read those news emails on the Palm $V$ organiser on the subway.

3 Inforover: I read news from Associated Press daily as well as the B BC website so always up to date on news. About $800-1000 \mathrm{~K}$ daily download.

4 Project@Hand: All our projects recorded in Project 98 are HotSync'd on my Palm V organiser so in meetings I am always prepared with the full details.

5 Thoughtmill: I use this for capturing thoughts and ideas for future reference. Very cool outliner. 
6 UltraMoney: Lastly I am so busy I never remember to balance my bank account, so now I view my bank statement in the Palm V organiser which comes from the internet via Ms Money 99.

These are paeons of praise in a utilitarian mode. However, they contain subtexts which delineate some of the ironies attached to inviting a machine in to help organise (run?) your life. One of these ironies is the question of who (or what?) is organising what (or whom?). For example, what kind of self-discipline is involved in using a Palm as a tool and what is it like living with the tyranny of infallible and literal memory? Who may co-opt this memory in order to discipline the user across spans of space and time?

User 2, for example, begins with standard praise for the Palm as a "productivity tool". However, the subsequent description of the Palm-in-use as a "critical part of my life" makes us wonder what kind of tool this is. It seems that in order to use it in the volatile context of the financial services industry, user 2 must subject himself to a strict daily regimen of data gathering and digesting. Given how much of his workaday efficacy is delegated to the Palm, anything less amounts to functional failure of user 2 in his business context. User 2's subtext contrasts with the paeon to efficiency in the main text; it is actually a confession of subjection to the device. Perhaps this is not adequately put. The point is that the Palm organizer enables user 2 to arm and discipline himself in accord with his employer's needs. The impression is not that user 2 thus "wins time" for himself but rather that, thanks to the pervasive role of the Palm in his life, user 2 is able to mould himself into a more perfect employee of the bank (and hence, presumably, advance his career). The Palm thus effectively becomes a personalised tool for translating the demands of employment into a self-imposed regime. But then whose tool is it, and what exactly is the status of a human actor "armed" with a Palm or, perhaps, "chained" to a Palm and subject to its tyranny of perfect memory?

This simultaneous exercise of self-discipline and other-discipline by means of the Palm also extends to private and romantic matters, as the following citation suggests.

\section{USER 3}

I've just received a Palm I I I ${ }^{\text {TM }}$ connected organiser as a Christmas gift from my husband and I must say I am in love... Not only have I dumped every contact name I have into to this sexy device, but the design of this device fits my hand like a new friend.

Although my husband does not mind my new found love affair, he has insisted that I pre-schedule time with him and is quite pleased with him- 
self over the control it provides him to gain access to my schedule. He has even pre-programmed a year's worth of scheduled "dates" and set up the beeping mode, so I won't forget. What a sweetie, xxoo.

PS: He doesn't know a thing about computers, so he must have worked late into the night to figure out how to enter in all the information and get it to work.

Great work in the design and layout. All I can say is ooh-la-la.

In this three-player figuration (user 3 , her husband, and the Palm) the Palm mediates the availability of user 3's time. In particular, the husband has coopted the Palm to stake romantic claims to his wife's "schedule", claims which user 3 coyly allows the Palm to register and which she suggests she will honor. But explicit sex seems reserved for the Palm itself. User 3 claims to be "in love". But is she in love with her husband for giving her the Palm or in love with the Palm? The husband is "a sweetie", but the Palm is "sexy", it is "a new friend", and all user 3 can say is "ooh-la-la". Is user 3 simply the Emma Bovary of the informatics era, or does she constitute a new exotic-erotic kind of cyborg together with her Palm? Is the nature of the Palm, its "features" and "design", responsible for this romantic drama?

What do we learn from this? In the first place, that we need to take a second look at the facile ontological division between humans and "things". This does not mean throwing it overboard without further ado. The Palm testimonials suggest that it is often difficult to decide who (or what) is programming whom (or what). The human agent disciplines the Palm to provide certain information on call, but the Palm subsequently turns around and disciplines the human.

What can we mean when we say the Palm "disciplines" the human? It is a simple enough matter to assert that the Palm is an "agent" and thus "acts", but what does this mean sociologically speaking? Few would be prepared to endow the Palm with the same quality of sentience and reflexivity as ourselves, so that its "acting" must be of a different order. It is clear that a Palm devoid of a human is meaningless; it is simply an orderly configuration of elements with particular performative potentials. This does not hold for the inverse, i.e., a human without a Palm - however much Palm Inc. may try to convince us otherwise. So-as long as the device is working to rule-agency can be attributed to the Palm only in a derivative and ironic sense. The Palm acts on its human operator, but only by a kind of blanket permission, on the basis of a prior compact by which the human sets the Palm up to exert discipline over him- or herself at some future time. The agency of the Palm thus derives from the voluntary submission of the human to demands made by a past self on a future 
self. The Palm's infallible memory becomes an instrument for storing demands on and information relevant for the future self. Like Marx's worker, the human actor is confronted by a temporarily alienated form of his own intentionality locked up in the microcircuits of the Palm. Could this be the (narcissistic) secret of the Palm's erotics? Inasmuch as the future is unpredictable, the moment at which the Palm presents its alienated demands may be totally inappropriate and may conflate past and present in odd ways. This amplifies the illusion of the Palm's own agency. The Palm cannot of course do more, nor less, than it is instructed to do, but the precise circumstances in which it does what it must can change the original meaning of the information entered in the past. In this sense the "detour" of the Palm has introduced an element of creative novelty into the ongoing self-organisation of the human. The Palm as partner in the reflexive self-discipline of ongoing life transforms the human actor into an informationally competent and punctual actor-but also an actor set up to be invaded at times by his own past intentions. This actor is a hybrid actor, a human-with-Palm, a "palmed Human".

We must conclude that the issue is not so much whether humans or "things" have agency, but that the agency of humans and things, such as it is, is modified by the "hybridisation" of agents in the form of humans-with-tools. In more general terms, human agency is so transformed by the technologies involved in the constitution of that agency, that in a technological age it does not make sense anymore to speak of human actors apart from their technological accoutrements. Unlike a rose, a Palm user is not a car driver is not, as we shall see, a designer of superconducting solenoid magnets.

\section{Designing magnets for the G-2 experiment}

Experiments in high-energy physics are organised as collaborative efforts among a number of locally based physics groups. Typically, the collaboration is sited at one of the large particle accelerators, and participating physicists fly in to attend meetings and participate in the ongoing work. To perform their experiments, the collaborators must first design and construct a "detector". These detectors transform the streams of high-energy particles produced by the accelerators into "events" that physicists can study. Detectors are typically large and complex devices, taking many years to design and construct. This process, even though the setting is exotic, is typical of design processes in general and reveals a basic feature of technology, namely that it is purposively constructed in order to perform a particular function. This does not rule out that designers may disagree on the function to be performed and especially on the way to implement the desired function in a design. 
The following account of the design of a component of a high-energy physics detector shows both the purposiveness and the contentiousness of the design process. The component in question is a $14 \mathrm{~m}$ diameter superconducting magnet ring for the Muon g-2 experiment which has been on-line at Brookhaven National Laboratories at Upton, New York, since 1998 (Disco 1998). The purpose of the experiment is to measure the so-called "anomalous magnetic moment" of a particle called the muon to a hitherto unprecedented degree of precision. This requires an extremely strong and very precise and uniform magnetic field along the entire length of the $14 \mathrm{~m}$-diameter coil. This was terra incognita for magnet designers and in fact proved to be a formidable engineering challenge.

It took only a few meetings of the magnet coil group to discover that there were serious disagreements on at least four aspects of the coil design. The minutes of Feb. 12, 1987, indicate that for each aspect, two main options were under discussion.
A Winding configuration: "pancake" vs. "continuous" or "zig-zag".
B Material for the coil mandrels (supports): aluminum vs. stainless steel.
C Winding technique: "ferris" vs. horizontal.
D Method of coil-cooling: Epoxied package in contact with liquid He cool- ing tubes vs. Immersion of coil package in liquid He cryostat.

Not all combinations were being pursued, so that in practice only two or three coherent "designs" were actually circulating - each championed by one of the participating groups. In the coil-group minutes, several of the alternatives were evaluated as follows:
A2 needs more delicate filling of voids; B1D2 needs welding of the alu- minum coverplate, very risky; $\mathrm{C} 2$ needs tall building; $\mathrm{B} 1$ allows extru- sion of the aluminum profile, cooling tube for liquid helium included. ${ }^{3}$

In the Feb. 26, 1987 meeting, for example, the issue of mandrel material was discussed. RS (a Brookhaven physicist) argued for stainless steel because "the pitfalls are best known". This provoked $\mathrm{FK}$, the CERN physicist chairing the group - and also writing up the minutes - to the following encomium on aluminum:

This does not rule out aluminum cryostats! Any proposition, reasonably worked out, will be thoroughly discussed, since we are all aware that aluminum allows extrusion, incorporation of helium cooling duct, vastly superior heat conduction and absence of magnetic disturbance. 
On March 26, there was a joint meeting of the three groups then working on different aspects of the detector design. The chief engineer of the coils group reported as follows:

\begin{abstract}
The group struggles with the material for the helium vessel: stainless steel or aluminum... stainless steel is more conservative, but the extreme slenderness of the coil section with respect to the coil radius made us look for other material combinations in which an aluminum tank or aluminum strips wound together with the conductor are possible alternatives. The conductor fabrication is under control. The leads are, as always, difficult to realise, in particular for the outer coils, where they have to pass through the back leg of the magnet. The coil winding is still under discussion. The coil support is tricky because of tight space, large forces, and low heat loss. ${ }^{4}$
\end{abstract}

The battle over winding methods was particularly fierce. On April 28, 1987, the chief mechanical engineer of the Yale group published a memo on "Evaluation of Superconducting Coil Concepts" again advocating "continuous winding" as opposed to so-called "pancake winding":

We find that during several meetings of this subgroup the general tendency was mostly in the direction of pancake coil construction. As a matter of fact, continuous winding coils were not seriously considered, and the strongest argument was that pancake was "the way it was always done". (Disco 1987)

In the event, the entire controversy was settled several months later by the intervention of a group from the Japanese national accelerator facility KEK. This group had a novel idea - already implemented in smaller magnets - for winding the coils "inside-out", i.e., from the mandrel inwards. Moreover, the group had a generous budget and offered to supply a quantity of "spare" superconductor material. Within a month, the virtues of the KEK design had dissolved resistance in the coil group, and it had become the preferred design for the coil configuration and winding method. Although its implementation was still far from routine, the design was sufficiently coherent to resolve the other bones of contention which had paralysed the group until then.

This "design parable" differs from the first one about the Palm organiser. It shows another, but equally fundamental, "phase state" of technologies. While the parable of the Palm showed technology as a device-in-use, modulating agency and social order in a wide range of social settings, the parable of the 
muon g-2 coils shows technology in the laboratory, as a device-in-the-making: an as-yet-uncertain crystallisation of social purposes in a material configuration. Several points should be emphasised:

1 The design process is an effort to define and master the future behaviour of an artifact. We should add: not only its manifest and desired properties, as in the g-2 example, but also its intended and unintended side-effects, dangers, and risks. Hence, understanding what goes on in the design process is a prerequisite for understanding the potentials of the artifacts that come out of it, or are likely to come out of it - although it is unlikely to be enough to predict the exact ways an artifact will turn out, i.e., its (quite possibly ambiguous) "societal career".

2 Artifacts are designed to function in stable and predictable ways. This encourages the use of non-living elements insofar as these are generally more stable and predictable - though often less flexible - than living elements like animals or humans. Superior stability and predictability are reasons why in advanced societies so much of human agency is "delegated" to machines (Latour 1987). Artifacts become important material anchors for social action, replacing older forms of co-ordination and socialisation. In high-energy physics with its demands for superhuman performances, such delegation is absolutely necessary - humans simply can't do the job - but the stability requirements are at least as critical. As the chief engineer of the coil group noted in a review:

\footnotetext{
The stability is a big problem: mounting concentric at room temperature, expecting it to be concentric at cryo-temp and last but not least cope with the expansion when the current is ramped up, while the outer coil is intrinsically unstable - all this demands superior engineering. ${ }^{5}$
}

3 Designers conceive of the artifact to be made as an actor. As they work, they are constantly trying to predict how the structure they are trying build will behave given particular arrangements and ambient conditions (Bucciarelli 1994). They do this on the basis of what they know about similar structures in similar situations as for example in the following commentary: "FK points out that the helical winding method leaves voids which are alternately on top or on bottom of the coil, but the magnetic forces tend to push them all to one side, hence half the layers may slip when the coils are energised" (minutes March 26). Some options seem beyond the cognitive pale. Then recourse is had to measurements, models, prototypes and calculations to acquire insight 
into expected behaviours. For example, the minutes of the coil group contain the following exchange. A physicist $\mathrm{s} \mathrm{K}$ is cited as predicting that "permeability variations in the stainless steel weld could be swamped by a strip of high permeability material". This prediction is qualified by the writer of the minutes as "a statement clearly in need of quantification and research on adverse effects".

The discourse of behaviours of these material structures is not of course a discourse of motives, intentions, and strategies such as would be the case were a political coalition the object of design. Here, and characteristic of technological design in general, the discourse of behaviours is of behaviours as governed by what, for lack of a better term, we call "natural law". Let us define this as the set of well-tested propositions and theories about how material objects behave under specified conditions. Canonical formulations of "natural law" (what we know about nature) are the substance of the textbooks of the natural and engineering sciences. The interesting property of natural law from the perspective of design is that it in theory allows for determinate predictions about the behaviour of material structures. Of course, this is only in theory. In practice, as the deliberations of the coil group make clear, there is always insufficient knowledge and insight, both into the properties of the structures one is building with and into the prevailing conditions they will encounter.

These conditions are in part also subject to "natural law", but in the final analysis they also include an encounter with society, with human organisations and purposes. In the case of the g-2 experiment, this is the encounter of the detector with the standards of evidence prevailing in the high-energy physics community (Knorr-Cetina 1999). Are the magnets sufficiently stable and uniform to warrant confidence in the data and the conclusions they have helped to produce and which they tacitly underwrite? For other design projects like microwave ovens (Cockburn and Ormrod 1993), diesel engines (Hård and Knie 1999), or storm-surge barriers (Disco 2002), this encounter occurs elsewhere and in different contexts, but inevitably it does occur.

In this view, design is nothing more nor less than a process of incorporating nature into society. The result is neither the one (classical Nature) nor the other (classical Durkheimian society as "moral order") but a thoroughly hybrid sociotechnical order in which machines, tools and devices co-act with humans. What these artifacts do, and can do, and what humans do, and can do, are profoundly altered by the new hybrid juxtapositions - by technologyin-society. This is why design engineering is not enough, but also why classical sociology is not enough.

4 Although not highly visible in the g-2 account itself, this hybridisation of actors and agency occurs not only in contexts of use, as in the Palm parable, 
but also in contexts of design. Indeed, how could it be otherwise, since design contexts are also contexts of use, albeit not of end-products, but of testing devices, prototypes, materials? The point is that design (and certainly design in an esoteric field like high-energy physics) is itself accomplished by hybrid actors. Physicists and engineers would be powerless without an elaborate array of measurement and test devices which enable them to assess the consequences of different design decisions prior to committing significant resources of time and money.

\section{Human calculators}

... I shall give a brief excerpt from the memoirs of an early member of the W PA Mathematical Tables Project in New York City. This project was established in 1938 with a very small number of mathematicians and a fairly large number of people from the relief rolls of the Depression. The people who came from the relief rolls were a varied sort, and more than rusty in their arithmetic. Therefore, they were divided into four different groups. One group was to do addition, a second group to do subtraction, a third to do multiplication, and the fourth group to do division and check the results. The people were installed in an abandoned stable in New York City, and the four groups were seated facing the four walls of the room. Each group faced a wall on which there was a large poster giving them their most important instructions, and to keep negative numbers straight, each person was given both black and red pencils to work with. The poster giving instructions for the addition group said:

Black plus black makes black.

Red plus red makes red.

Black plus red or red plus black, hand the sheets to group 2. (Slutz 1980, 471)

What is disturbing about the situation described in this citation? It is of course the panoptical nightmare, the Orwellian dystopia of reducing human beings to cogs in a machine. Humans here were operatives possessing fragments of instrumental competence. The whole, the calculating machine which they produced by their fragmented labours, had no meaning for them; it added up only from the perspective of the expert masters.

The Mathematical Tables Project exhibited a shocking disregard for modernist distinctions between humans and machines. The project mobilised all the usual Taylorist ploys in order to transform intransigent human workers 
into obedient functionaries. Skills were fragmented, categorised and apportioned to different workers according to ability. Rules of procedure were thoroughly explicated and reinforced by texts and material cues and instruments. Routing of work followed explicit instructions allowing the minimum possible of individual discretion: "Black plus red or red plus black: hand the sheets to group 2".

Therefore, the question this example raises is the following: How is the Taylorised human-based calculating collective designed and operated by the mathematicians of the W PA Mathematical Tables Project any different from, say, the gear and relay-based desk calculator or the silicon-based modern digital computer? If there is no practical difference, what are the consequences for the classical attribution of agency (morality) to humans and of mere mechanical functionality (instrumental means) to artifacts composed of nonhuman components? To turn Primo Levi around: "What is an artifact?" Or better perhaps: "What is an artifact made of?"

The physicists and engineers in the g-2 story seem to be busy designing an artifact composed entirely of nonhuman components. In this design process, humans (except, of course, the designers themselves) seem a long way off. But ultimately they are there in the form of the physicists who are going to have to get the detector to produce compelling data. The physical detector must be designed to take its part in a "hybrid ensemble" (Callon and Law 1995) consisting of the machine and the physicists and engineers who will ultimately use it to produce data about the muon. In the context of high-energy physics, where the always minute data traces are easily wiped out by systematic or transient "noise" in the detector, operability means total transparency. Physicists must know at all times what the precise condition of the detector is so that they can distinguish data from noise (Knorr-Cetina 1999). This knowledge is based both on a priori confidence in the stability and performance of the machine and on real-time monitoring of its performance. Both modes of confidence depend on crafty design. Hence, although the proximate design labour described above concerns the construction of a nonhuman apparatus, i.e., a machine in the classical sense, the mediate aim is a "hybrid collectif" (Callon and Law 1995) involving both human and nonhuman components.

The notion of "hybrid collectif" suggests a spectrum ranging from artifacts with predominantly nonhuman components to artifacts with predominantly human components. The g-2 magnet coils are clearly very near the purely nonhuman pole, and the WPA Mathematical Tables Project is very near to the purely human component pole. However, just as the g-2 magnet assembly-in-use will not be purely nonhuman, the human calculator is not purely human. The human calculator is again a "hybrid collectif" consisting 
of human operatives and overseers, but also of a set of tools and props: coloured pencils, paper, texts, chairs, tables, etc.

The sociological reflex encourages us to call the human calculator an organisation with strict rules, hierarchies and bureaucratic discipline. This is because it appears to be an orderly and centrally disciplined arrangement of human actors. What advantage is there in thinking of it as an artifact in a class with the Palm organizer or the g-2 coils? Only this: it encourages us to look at this organisation of humans and things as an instrument craftily designed to perform specific functions in a stable and predictable manner. It is a well-ordered factory for the dependable production of correct answers to sums. So the WPA human calculator is no less a piece of technology and as much of an engineering achievement as the Palm or the g-2 coils. We might say that the W PA human calculator could pass an ironic Turing Test for being a machine.

However, the process of designing with nonhuman components is a different kettle of fish from designing with human components. This has to do with how designers can impose stability and predictability on the different kinds of entities. A first-order distinction would be to say that nonhuman entities must be disciplined by means of Baconian ruses, i.e., by mobilising natural law, while human entities must be disciplined by Benthamite panopticism, i.e., by surveillance and the judicious application of the carrot and the stick. The point is that entities subject to natural law can be disciplined (made stable and predictable) by embedding them in the right material configurations - at least as far as our knowledge and insight reach. Human entities must be convinced, cajoled, and coerced to impose self-discipline, inasmuch as it is impossible to control or predict movements, let alone thoughts, in sufficient detail to guarantee useful and predictable performances. As with Taylor's famous 2-dollar-a-day man, the human entity has to be made to want to perform to rule. Engineers burdened with the design of large hybrid technological systems like urban water supplies and electricity systems are constantly faced with the problem of having to convince users to behave according to the dictates of the artifact-system as a whole.

The w PA Mathematical Tables Project shows that in a pragmatic sense, humans cannot simply be defined as agents. They can rather easily be made into components of artifacts - as indeed the history of industrialisation amply attests. These artifacts act, but not according to the will of the human components, but - if all goes "well" - as projections of the interests of their designers and masters. 


\section{Enschede: the explosion of S.E. Fireworks}

On the afternoon of May 13, 2000, a hot and sunny day, a series of explosions ravaged the neighbourhood of Roombeek in the northern part of the Dutch city of Enschede. The culprit was a fireworks storage and assembly facility called S.E. Fireworks. A fire on the grounds had somehow ignited explosives stored in a set of reinforced concrete bunkers; the ensuing blasts ripped the bunkers apart, shelling the surrounding area with chunks of reinforced concrete and igniting countless secondary blazes. In the space of 15 minutes the neighbourhood was reduced to smoldering ruins. Amazingly, only 20 people were killed, though many more were injured. Property damage was extensive.

S.E. Firework's highly visible and dramatic activity on that Saturday afternoon stood in stark contrast to its prior "behaviour". Somehow, the normal peaceful routine had broken down, and what we might call a "catastrophic deconstruction" of the facility and its immediate environment ensued. We have come full circle from the Palm parable to consider another artifact-inuse. But now, instead of an artifact working-to-rule, we have a disaster whose short-term effects seem to have left little room for "user interpretations". What can this "accident" teach us about humans, nonhumans and the dialectic of agency and structure; in short, about technology and sociology?

The leading question is whether we should see S.E. Fireworks as an agent or as a structure and, ipso facto, whether we should see the disaster as an eruption of agency or as a collapse of structure. Secondly, though primarily, we should sort out what kind of agency/structure we are dealing with. Are we talking about human organisation, about reflexive human agency, about a technical system and its associated failure modes? In short, how ought we to describe S.E. Fireworks, and how ought we to explain the explosion?

Let us start by noting that, until the moment of the explosions, the residents of Roombeek considered S.E. Fireworks as just another unremarkable small-scale industrial facility on the edge of the local industrial park. Few even knew that there were fireworks stored there. The municipality was of course informed and exercised its statutory right to perform periodic inspections and to provide permits for what was most certainly - and certainly in retrospect - a hazardous activity. It seems that to the extent Roombeek residents knew what was going on at S.E. Fireworks, their perceptions of fireworks as harmless entertainment and their trust in the city to enforce the necessary safety regulations suppressed any overt concerns. Testimony after the explosion corroborates this.

What kind of entity was S.E. Fireworks before the explosions? It was clearly what sociologists call an organisation, i.e., a structure of more or less well-de- 
fined role sets with incumbents more or less performing to rule (Crozier 1977). Presumably, there was more slippage in role performance in the routinised structure of S.E. Fireworks than in our earlier example of the panoptical w PA Mathematical Tables Project, but in essence they were similar entities. ${ }^{6}$ On the other hand, S.E. Fireworks was also an "agent," even in its predisaster days. It was a legal entity one could call on the phone, make deals with, inspect, grant permits, and assign responsibilities. It was a significant player in the specialised custom-fireworks market. This double identity is hardly surprising, in fact, it is inherent in being an agent, inasmuch as agency (of whatever kind) presupposes a structured actor. The agent (or actor/actant) is always also a structure composed of sub-entities, and it is in fact by dint of analysis of that structure that the potentials for agency may be assessed. Classical psychoanalysis has exactly the same kind of deconstructive ambition with regard to the structure of human agents - in effect, postulating a structure of sub-agents like the id, ego, and superego that performs the aggregate agency of the person.

This ambiguity about agency and structure is not a problem because it does not compromise the agency-structure dialectic as an analytic scheme for tying together order and change and past, present and future. Agency and structure remain different although mutually constitutive aspects of entities. The difference is simply a matter of different levels of analysis and aggregation. ${ }^{7}$ What is worrisome, however, is that sociologists persist in excluding technology from this dialectic - especially considering the explosive potential of some technology-rich organisations. ${ }^{8}$

The mutual implication of agency and structure and the exclusion of technology from sociological accounts holds a fortiori for the explosions themselves. Again, at a certain level of analysis, for example if we are concerned about the effects of the explosions on the physical, social, or political environment of S.E. Fireworks, we can black-box the structural complexities of the facility and treat it as a singular agent - albeit an agent gone beserk. However, if we are interested in the causes of the catastrophe, for example because we want to assign responsibility in connection with political and legal claims, then we shall have to unpack the structure of the facility (and perhaps the history of its facilitations by other actors). In particular, we shall have to focus on the constitutive actors/actants whose orderly and ordinary interactions constituted S.E. Fireworks as a (quasi)-stable enterprise. Clearly something out of the ordinary must have triggered the catastrophic breakdown of structure which transformed S.E. Fireworks into a raging monster. How do we go about describing this deviation from normalcy and its catastrophic consequences? Two hermetic idioms, "natural law" explanations and sociological explanations, are at our disposal. 
Adherents of "natural law" would say that certain chemicals stored inside of concrete bunkers and sea containers caught fire and that as a result an explosion ensued that caused large chunks of the bunkers and containers to pepper the surrounding neighbourhood. Regarding this account we have, sociologically speaking, very little to explain. We could elaborate our "natural law" explanation, invoking chemical and physical theory to explain the causes of the explosion and the pattern of destruction that ensued. The points of departure are the physical properties of the materials, their disposition on May 13, 2000, and the presence of fire on the grounds of S.E. Fireworks.

A sociological explanation would argue that because certain employees were not being alert (maybe because it was very warm weather), because the company was forcing them to violate safety regulations or because the division of labour was such as to encourage miscommunication and accidents, a destructive explosion ensued. Here, we certainly have some sociological explaining to do. But we would miss the physical causalities involved in the explosion and hence, somehow lose the specific technological dimension of the accident - except to note that the failure of human discipline was contingently attached to highly destructive natural forces.

In practice, we see both kinds of discourses being used to deconstruct or "reconstruct" accidents like this. There is a well-developed discourse of technological risk which concentrates on the physical etiology (what sequence of events must have taken place in order for such an accident to occur) and which may point to human error as a contributory factor. There is also a discourse derived from organisational sociology which combines this approach with a focus on the human and organisational sources of such accidents (Perrow 1984). Here we can begin to see the humans and the non-living components as part of a single sociotechnical gestalt - as a technological-organisational hybrid with an innate proclivity to malfunction which is almost as "normal" as its proclivity to perform as planned. Diane Vaughan has demonstrated the strength of this approach in her analysis of the Challenger Space Shuttle explosion (Vaughan 1996). This is a promising avenue of approach because it understands technology as nature-made-social, as immanently composed of both non-living and human elements. It is a style of analysis which points the way to understanding S.E. Fireworks not as an ontological dichotomy, i.e., a physical structure on the one hand, and a human organisation on the other, but as a "hybrid artifact" consisting of patterned interactions between both non-living and human elements. What we require in order to analyse the explosion socio-technically is to be able to speak of nonhuman elements-in-use. We may need to have recourse to naturalistic explanations, but only as links in a chain of reasoning which inevitably also in- 
cludes human intentions and (dis)order. The work of Perrow et al. clearly points to a sociology of technological culpability.

But if we want to speak of S.E. Fireworks as a latent agent that sprang into action on May 13, 2000 (or for that matter, as an apparently stable structure that deteriorated catastrophically on that date), then we still need to qualify the notion of agency involved here. Except at a formal level, i.e., in regard to the schemata of structuration referred to in the introduction, the agency of non-humans has a different logic than the agency of humans. Callon and Law, for example, argue for a differentiated notion of agency for different kinds of what they call "hybrid collectifs":

\begin{abstract}
...translation does not have to take the form of language. For here is the bias, the logocentric bias which runs everywhere through social theory. The bias in favour of the speakable.... Which is why, though we cannot, to be sure, say very much about it, we do not wish to link a notion of agency to linguistic re-presentation. For signification ... is more general than talk. It comes in all kinds of forms. And some, though only some, we can imagine. Others, no doubt, we will never know. Which means that there are multiform kinds of agency: forms of agency that we can't imagine; forms of agency performed in patterns of translation that are foreign to us; forms of agency that are, for instance, nonstrategic, distributed, and decentred. (Callon and Law 1995, 503)
\end{abstract}

Though Callon and Law might well reject this solution, we have considered the possibility of qualifying the agency of nonhumans as agency subject to "natural law", e.g., the laws of physics or chemistry. However, S.E. Fireworks was not merely composed of nonhuman beings; it was a "hybrid collectif" in which humans and nonhumans were intimately juxtaposed and mutually transforming. Its agency was thus amenable only to explanations which somehow combine "natural law" and classical sociological explanations. This is the challenge, not only for scholars of technology, but also for commissions investigating the "causes" of such disasters.

\title{
What is technology?
}

Our four parables have given us important insights into technology. These can be summarised as follows:

1 The user testimonials about Palm organizers question the simple notion of the artifact-as-tool and hence of the actor as unproblematic tool-user. The 
simple notion of a tool is: an artifact that an intentional subject uses to get a specific job done. There are several points that need elucidation: How must the Palm be shaped and disciplined in order to use it? What self-discipline must the subject impose on him or herself in order to be able to use the Palm as a tool at all? How does the Palm discipline the thoughts and movements of the user? In what sense do the user and the Palm compose a cyborg, i.e., in what ways do the Palm and the human user become a single hybrid actor?

2 The high-energy physics story reminds us that technology is not only a set of material structures that we live with and that transform us, but that they are intelligently and purposively designed to perform particular functions vis-à-vis agency and social order. This does not imply that the intended design completely maps the design in use. Maximising this mapping is a major problem for designers, developers, and (sometimes, as in this case) users. The design process is therefore contended and negotiated and thus constitutes an authentic field for sociological study.

3 The story of the "human calculators", i.e., humans organised and disciplined by means of panoptical and Taylorist methods to do calculations for making mathematical reference tables, argues that the stuff of which artifacts are made makes no principled difference to defining and using them as means - even if, as in this case, that matter is human brains and bodies. The inverse point is that the presence of human brains and bodies does not necessarily imply the presence of human subjectivity, e.g., free will, imagination, spontaneity, etc.

4 The S.E. Fireworks story makes two new points and also recapitulates lessons from the other three stories. The new points are, first, that agents are also structures and, symmetrically, structures are also agents. The distinction rests on levels of analysis. Almost as a corollary, it follows that a breakdown of socio-technical structure can be analysed as agency of the structure vis-à-vis its context (of other structure). Points from the other stories are recapitulated as follows:

- S.E. Fireworks, in both its stable and unstable manifestations, was a "hybrid collectif" just like the "cyborg" Palm+user.

- Like the WPA Mathematical Tables Project, S.E. Fireworks incorporated human actors as stabilised ("translated") entities of its process. These were also implicated in the structural breakdown.

- S.E. Fireworks, like the muon g-2 coils and indeed artifacts in general, was a constructed "hybrid collectif" for whose behaviour and misbehaviour the designers and maintainers share responsibility. 


\section{Conceiving a sociology of technology}

How can this Protean phenomenon called technology be incorporated into mainstream social theory? The field of Science and Technology Studies has by and large set itself up as an alternative, rather than a corrective, to the classical sociological canon. Symmetrically, there is still little interest within mainstream social theory for the accomplishments of the new technology studies, in spite of the evident impacts of new technologies.

There are a few ridge-riders, however, who are claiming that classical social theory and technology studies have mirror-image strengths and weaknesses, and would profit from a synthesis. Where classical social theory is able to conceptualise large-scale changes in the historical landscape and has a vigorous sense of structural constraint, technology studies seem limited to contingent and local explanations of mere episodes. Conversely, where technology studies have developed subtle methods of understanding technologies, classical social theory is still at sea when it comes to thinking about the technological dimensions of social order and transformation. Hence, these authors argue, there seems every reason to try to formulate some kind of synthesis not based on an a priori rejection of classical sociology. We shall take a look at three of these efforts.

\section{The perspective of the user}

Mark Shields argues that sociological efforts to comprehend technology - including the new technology studies - are all in thrall to what he terms an "instrumentalist" conception of technology. "Instrumentalism" for Shields means understanding technologies as "purposive instrumentalities whose relevant explanatory properties may be described exhaustively within a framework of means-ends rationality" (Shields 1997, 190). Because of this "instrumentalist" perspective, which positions technology in a sphere of rational, pre-social phenomena, classical sociology tends to ignore technology. Weber's disdain of means-ends rationality as the "degree zero" of social action, no less than Pareto's distinction between logical and non-logical action, has encouraged sociologists to cede technology to the sphere of science and economics. Marx, of course, also saw technology as primarily a product of economic calculation, as machines whose forms were shaped by the exploitative ambitions of competing capitalists. Ironically, Shields argues that even the new technology studies - however salutary their redefinition of technology as an inherently sociological phenomenon - do not escape this instrumentalist horizon. Even here, technologies are seen as products of instru- 
mental design, of efforts to produce specific use-values for specific social groups.

According to Shields, the way out of the instrumentalist trap is to look at technologies in use. The social meaning of a technology is not what its designers claim it to be, but in what users make of it. Shields formulates this as a principle of "instrumental underdetermination", as a failure of instrumentalist intentionality to exhaust the social meaning of a technology. Shields, in fact, seems to be arguing that the sociology of technology only properly begins at the point where users take over from designers to integrate artifacts into what he calls "sociotechnical practices". "Technological artifacts are thus polysemic, because different agents - inventors, designers and users - employ schemas, or 'frames of meaning' ... that render artifacts 'capable of being interpreted in varying ways'". A variety of agents, working with different perspectives, constitute "sociotechnical practices" around specific artifacts or technological systems and provide the proper subject matter for the sociology of technology.

Quite aside from the question of whether Shields' characterisation of new technology studies as essentially instrumentalist is apposite - which I think it is not - the overall point is well taken. Clearly, when we focus on technologies-in-use instead of only on technologies-as-instrument (as material means for attaining specific ends), we uncover a rich sociological and anthropological dimension to technology which, moreover, can be approached with traditional theories and methods. On this view, technologies are not some non-social bit of logical action, but become societal constructs, just like laws, religions, norms and the other furnishings of classical sociological theory. Technologies, in this sense, become sociological objects in an immanent and transparent way and are no longer sociologically inexplicable intrusions into the social from some other realm.

However, Shields's rejection of "instrumentalism" throws out the baby with the bathwater. There is a difference between asserting that technology is only an instrument, and asserting that it is that, but also many other things as well. I think Shields fails to make this distinction and in a shortcut effort to redefine technology as sociologically "just folks" wrongly quarantines the instrumentality, which makes technology such a unique and pervasive sociological phenomenon. The g-2 coil story - which, in spite of its exotic context, seems to me on this point perfectly generalizable to all kinds of other technologies - makes quite clear that artifacts are designed as "purposive instrumentalities". In design, as Bucciarelli (1994), Henderson (1999) and Vincenti (1990) make plain, artifacts-in-becoming are, as Shields puts it: "described exhaustively within a framework of means-ends rationality". That is indeed 
the business and logic of design. The question then is: what is the relation of design as a specific subset of societal practices to the ultimate working of artifacts in society?

It is true, as Shields argues, that design suffers from "instrumental underdetermination". Its instrumentalist horizons do not indeed exhaust the possibilities of artifacts-in-use. However, "instrumental underdetermination" is not an argument for the irrelevance of design, nor for the irrelevance of a sociology of design. It is only a powerful argument for also including actual "sociotechnical practices" in our perusal of technologies.

Although there is unquestionably some slippage between designed artifacts and used artifacts, this is certainly a question of degree and differs according to the type of artifact. While a knife may be designed as a weapon, it can also cut bread. The Palm Organizer, designed as an electronic appointment book with note-taking facilities, has been seized upon by users and programmers and endowed with a plethora of non-intended uses and identities. The g-2 coils, on the other hand, are such complex and dedicated pieces of equipment it is hard to imagine another use which exploits their essential design features than the one for which they were in fact designed. ${ }^{9}$ It is also not easy to imagine that the ultimate users will develop significantly different operational protocols from those developed in the design phase. This suggests two untested and speculative first approximations about the relationship between design intentions and ultimate use: First, the complexity of an artifact is something like inversely proportional to its flexibility-in-use. Second, the more context-bound an artifact, the less likely actual use will deviate from the use envisioned by designers. These propositions want testing, but even in this tentative form they suggest that care should be taken in divorcing uses (and effects) observed in practice from uses previously envisioned in design.

In general, a principle of "limited flexibility" seems apposite, stating that the way artifacts are designed is more or less consequential for the way they will ultimately be used. Products may in fact be specifically designed with what might be called a "topography of use", i.e., gradients encouraging and discouraging particular uses. Users can sometimes get around such design topographies, but if the designers are on the ball, only at costs which may in fact be disheartening.

\section{Having the post-modernist cake}

Fran Collyer (1997) is not so worried about "instrumentalist" biases in technology studies. Nor does she advocate a new focus on technology-in-use as a remedy. At another level, however, she shares Shields's concerns of how to 
merge "post-modernist" theories of innovation associated with authors like Callon, Pinch, Bijker, Latour, and Hughes, with more generic social theory. As she puts it:
Although post-modern perspectives have correctly identified the emer- gence of a greater diversity in social relations and broken down the dis- tinction between subject and object, post-modernism is too often con- sidered in terms of a total replacement for structuralist sociology. In its stead, it is suggested that the insights of post-modernist theory be added to the sociological 'armory'. Such a merger would allow a better integra- tion of theories of technology and society. This would produce a more adequate theory of invention and help to explain how social inequalities shape the invention process. (Collyer 1997, 203)

To achieve this merger, it is essential that post-modern theory abandon its posture of splendid isolation. Moreover, it contains a number of flaws which must be remedied before it can be "added to the sociological 'armory".

Collyer seizes upon Callon's "translation networks" as the paradigm to be criticised (Callon 1991). The first problem is that the model "offers insufficient explanations for the relationship between the actants or the differing capacities of the actants to direct and control the invention process.... the actions of some actants (such as an individual or group) are both quantitatively and qualitatively different from the actions of other actants (such as a computer or an amoeba)" (Collyer 1997, 199-200).

This lack of what we might call sociological relief of course inheres in the notion of "actant". The whole point of the concept is to denote a relative or momentary "phase state" of an entity: that which in a given situation is initiating a transfer of "intermediaries" (instead of itself being transferred). So the notion of "actant" has no essentialist connotations. It is only a role in the network dynamics which every entity (human or non-sentient) can at times play. We have seen in the case of S.E. Fireworks that the explosives were transformed from intermediaries into very forceful actants, and in the case of the w PA Mathematical Tables Project that the human calculators, agents all, were reduced to "mere" intermediaries. However, from a traditional sociological perspective this structuralist focus on network dynamics at the expense of ontological veracity is, as I argued above, immensely unsettling, and Collyer's criticism here is directed at just that point.

From the point of view of an adequate sociology, it would be desirable to have some indication of the relative chances of different kinds of entities (e.g., humans or non-sentients) of becoming either actants or intermedi- 
aries. We would also want to know how different types of entities change phase, i.e., change from actant to intermediary and vice versa. What types of processes involving what types of other entities typically induce this transformation for different kinds of entities? In the context of the S.E. Fireworks story, for example, I argued for a distinction between natural and human causality. Finally, what types of entities tend to be dominant in translation networks? Sociology has developed a vast conceptual arsenal for dealing with power relations and "life chances" among networked human actors; is anything like this possible when non-human or non-sentient actants get involved? Is there, to echo Marx, anything determinate in the final instance? Do the oysters, or do the walrus and the carpenter, typically carry the day? Or can we, like the carpenter, take stock only after the oysters have been eaten up?

Collyer also takes translation network theory to task on another count. She criticises it for what we might call its solipsism, i.e., its tendency to discount an external world. The focus is on the internal process. External "factors", limits and opportunities are simply not taken into account. Collyer says: "Theoretical disregard for the consequences of social structure means that the model over-estimates the capacity of scientists and others within the network to shape their own circumstances just as it under-estimates the impact of societal processes beyond the immediate activity of the actors" (Collyer 1997, 201).

This is a sociologically unexceptionable criticism. However, it does not absolve us from defining just what we mean by this "social structure" and explaining how it impinges on the ongoing structuration of the translation network under consideration. If the narrative strategy of Latour's Aramis is any clue, then the network approach solves the problem simply by subsuming all elements that have some bearing on the unfolding plot of the translation network into the network itself (Latour $1996^{\mathrm{e}}$ ). Hence, there literally is no external "social structure" or, rather, elements of that putative "social structure" are absorbed into the network as needed (both by the actants and the analysts). The network simply expands to cover the relevant turf. However, such rampant contingency literally robs us of a coherent vision of the social world and obviates the possibility of prediction and the hope for societal management of technological development.

But then, what is "social structure"? In one sense, it is only a bookkeeping ploy to distinguish what is transient and of immanent pragmatic or analytical interest from that which is more stable and lasting - and which is taken for granted as a background of available "rules and resources" (Giddens 1984) by both actors and analysts. And, in a historical sense, structure is a residue of agency. Factors, institutions and positions are built up over time and can per- 
sist thanks to the benefits they produce for the few or the many. These structures define cost-benefit gradients for different types of actor-strategies and thus shape dynamic social processes.

\section{New rules for a sociology of technology}

What clearly has to be done if the "merger" between "post-modern" theories of technology and sociology is to have a chance to align these two discourses in some way. Werner Rammert (1997), our final ridge-rider, has made just such an effort in the form of a new set of "New Rules of Sociological Method".

Rammert's twelve rules, a double-take on Anthony Giddens's (1993)take on Durkheim, are an attempt to define a general sociology capable of incorporating technology as a "social fact". Rammert's specific aim is to combine "a constructivist explanation of technology generation on the local level ... with a social evolutionary approach of structural selection on the global level" (Rammert 1997, 171). Like Collyer, Rammert criticises the new technology studies for their inability to comprehend large-scale structural processes. He shares Giddens's view that a rational sociology must "chart a course between interactionism and structuralism" (Rammert 1997, 173) and so he seeks to complement the "interactionism" of sсот (Bijker and Pinch 1987) and actornetwork theory with a "structuralist" mode of analysis. Rammert begins by defining what he sees as the essential sociological nature of artifacts. His first three rules reconfirm basic conclusions we drew from our technology parables, particularly the dual agent/structure nature of artifacts and the importance of design in establishing artifact properties and societal effects.

Rules 4 through 7 address possibilities for a sociological account of technology development. We are up a notch from the design floor. The argument turns on the concept of "technology projects". These are concerted efforts to combine inquiry into the unknown with routine resources in order to produce "an artificial and reliable technical system" (Rammert 1997, 180). The elements of such a "technical system" can be "physical effects, material artifacts, sign codes and habitualised routines". But note, not human bodies. Technical projects are theatres of social conflict and co-operation; a plethora of heterogeneous actors with different resources and following different rules do battle in order to project their own notions of order and utility onto the project in becoming.

Rules 8 and 9 take us a step further on the ladder of socio-technical aggregation. Rule 8 suggests ways of conceptually bridging the gap between local and idiosyncratic technological projects and the various "institutional fields" of society. If local projects aim at the constitution of a successful techno- 
structure (the context within which artifacts become operative), then this can only be achieved on the basis of "micro-politics of negotiation" between local actors and the macro-social networks. Rammert distinguishes four "fields": the scientific, the technological, the political and the economic. Science is about whether proposed operating principles are feasible. Technology is about defining standard procedures and acceptable interpretations of the "state of the art". Politics is about the ideological and political resonance of projects. Which particular variants will politicians back, and what are the legal and funding consequences? Economics is about techno-structures in the context of innovation within firms.

Rules 10 and 11 represent an effort to tie the level of concrete local projects, as incremental additions to the stock of technology, to the overall dynamic of technology at a global level. Rammert argues that on a global level the structuration process should be treated as "blind variation" because technoprojects are blind to long-term effects and have all kinds of "unintended consequences" anyway. Local activities of enrollment and translation in actornetworks are not undertaken with an eye to overall outcomes. They could not do so even if they would, because of the various "structural filters" - conceived as institutionalised patterns of constraints and enablements - imposed by the different fields through which technology projects must navigate. "... the operating filters are manifold, their effects cannot be precisely calculated, and ... they are developing simultaneously" (Rammert 1997, 184).

Rule 12 summarises Rammert's approach: "Technical change neither results from a structural logic of development that operates beyond the scope of social actors, as Durkheim's first rule may suggest, nor is it entirely open to voluntary action and various constructions of technology, as social constructivism may suggest" (Rammert 1997, 186). This general argument positions Rammert's rules squarely within structuration theory. Sociologically salient are all those mechanisms which encourage predictability and stability. As Rammert restates rule 12: "Structural filters which are institutionalised in the different fields of the innovations system reduce the principled contingency of technical change to certain corridors of technical development. But they maintain the status of stabilised technology only as long as social actors practically reproduce the techno-structures" (Rammert 1997, 187).

Rammert's overall effort merges core concepts from actor-network theory as articulated in the writings of Callon, Latour and Law, with Giddens's general theory of structuration. The keystone is the integration of different levels of analysis within the framework of an overall local-global dynamic. The local dynamics are contingent - as actor-network analyses keep stressing - even though - as Rammert stresses - they take place in the context of global struc- 
tures of rules and resources, i.e., in the context of field-specific "institutional filters". So even with the contingent variety produced at local levels, there is already steering of technological "trajectories" due to the impinging of more or less stabilised institutional structures. In this way technology is from its inception a "social fact", i.e., a structure explainable by recourse to other "social facts". In the best traditions of structuration theory, Rammert argues that these local projects culminate in new techno-structures which subsequently become part of the institutional order defining and shaping new technological projects. Levels of analysis are joined in the transitions between rules 4 and 5,7 and 8 , and 9 and 10 .

\section{Having the cake and eating it}

This said, our modest technology stories, no less than Shields's and Collyer's texts, justify taking a second look at Rammert's solution. While his finegrained proposal for joining classical sociology to the new technology studies seems a direct answer to Collyer's plea and is framed in the agency-structure dialectic suggested by our stories, there are still some worrisome points. In spite of Rammert's openness to "post-modern" technology studies, he does not offer quite the kind of solution Collyer seems to have in mind. Rammert gives a wide berth to just those "post-modern" elements of new technology studies that Collyer finds most intriguing. Likewise, Rammert's text is a red flag from the perspective of Shields's diatribe against "instrumentalism", despite Rammert's explicit rejection of an "instrumentalist" approach in favour of a "pragmatic" one (rule 3). Rammert's overall approach to technology is to view it as a societal problem-solving strategy centred on the design of artifacts. In so doing, he pays little attention to artifacts-in-use, although his framework does provide the necessary conceptual space. Insofar as use or users figure in Rammert's sociology of technology, it is all about representations by designers of such use: i.e., the "configured user" rather than the empirical patterns of use themselves.

Our technology stories concur in identifying these as serious gaps. A competent sociology of technology must encompass both the design of technologies and their societal implementation, or "use". Rammert's neglect of the latter aspect makes it easier for him to merge technology studies into traditional sociology. By concentrating on design, rather than use, Rammert can avoid the debate about the agency of nonhumans. Design is about the structuration of artifacts, i.e., about conceiving and building "techno-structures", a process in which artifacts are object, rather than subject, of agency. As Collyer sug- 
gests, the doctrine of nonhuman agency is the most radical attack possible on sociology as a modernist project. Rammert's focus avoids messing with traditional sociological ontologies; this is apparently the price he thinks he must pay to remain sociologically credible. In point of fact, he explicitly distances himself from what he calls "some exaggerations" of the actor-network position for their refusal to distinguish between "reflexive human agents and non-reflexive non-human agents" (Rammert 1997, 186).

So Rammert still leaves us with two knotty issues: how to sociologise technologies-in-use and how to conceptualise the agency of artifacts. On the basis of what has been said above, it should be possible in principle to distinguish a sociology of technology-in-use from a sociology of technology-in-design, although rarely will we be able to distinguish these as separate phases in practice. Our stories attest that all kinds of ironic and unintended effects can erupt when once-designed technologies are put to use, some of which will be quite oblique to the interests which framed the original design of the techno-structure itself. As noted, artifacts may have certain use-gradients "designed into" them, but they are far from impervious to redefinition, "misuse", or catastrophic failure when put to work in context (Fleck 1999).

As Shields argues, the "context of use" should not be seen merely as a sphere in which the artifact "ripens" as a "techno-structure", i.e., in which the potentials of the artifact are revealed in practice. It is at the same time a sphere in which the techno-structure reveals the potentialities it has for restructuring the societal context into which it has been introduced. The point is that the social context of use is modified or "evolves" in the very same process in which the artifact itself is modified and in which it evolves in new directions. This is part of the meaning of the "co-evolution" of technology and society. S.E. Fireworks was a dramatic example, but the Palm organizer and its fellow travellers will no doubt be more consequential in the long run. A sociology of technology-in-use would do well to follow Rammert's and Fleck's lead in distinguishing local, contingent contexts of use from more global structural and institutional contexts.

To my mind, there is little in Rammert's text to suggest that he would disagree with any of these points. The problem seems rather a matter of emphasis than the willful and thematic suppression of technology-in-use. Rammert's focus is on technology dynamics, the fountainhead and until recently the working face of new technology studies. Hence he elaborates on how criteria for new technology are established and on how resources for constituting new technologies are assembled, rather than on the effects artifacts and technological systems have on societal order, as modifications of agency and as new elements in the structural landscape. However, nothing suggests that 
Rammert is principally insensitive to these issues, and more importantly, there is nothing in his proposal that would militate against including technologies-in-use as an integral "phase" in the technological dialectic he proposes. A similar local-global logic would be apposite here, with locally contextualised usages generating varieties of experience and critique which would be differentially institutionalised depending on their resonance with different "institutional filters". The use of technologies and the transformations of agency and structure which that entails could be seen as a form of informal societal innovation subject to the same kinds of dynamics as the more formal innovation in institutionalised design settings Rammert now seems to be focussing on.

The agency of nonhumans is more difficult to incorporate into Rammert's new synthesis. He himself seems adamant in reserving agency to human persons, coupling agency irrevocably to "reflexivity". This is of course the classical sociological prohibition, and the question is just how forbidding is it? Does it in the end prevent us from realising Collyer's project of integrating classical sociology and "post-modern" technology studies?

I have already suggested that introducing nonhuman entities and heterogeneous types of agency does not compromise the dialectic of agency and structure as a sociological mode of reasoning and explanation. That is to say, deviant (in casu nonhuman) forms of agency do not compromise the dialectical core of classical sociology. What is compromised, however, is the classical logic of attribution, of explanation of actor behaviour as canonised in Max Weber's famous dictum of Verstehen. Without such possibilities for attribution, sociology is at sea; actors must be invested with valences, preferences, interests, etc. in order for their behaviour to be sociologically comprehensible, i.e., to be soziales Handeln in Weber's sense. Or must they?

In point of fact, it is my impression - though I can hardly prove it in the scope of this chapter - that sociology really has no deep or consistent definition of the homo sociologicus. ${ }^{10}$ From sociology's inception, the inner workings of human actors, by all accounts the constitutive elements of social order, have been black-boxed in order to throw up ramparts against the seductions of reductionism. Sociology's project is in a sense to deny human agency a reality sui generis. To put it very crudely: society is all; individuals are nothing. It is true that some 2oth-century American strains of sociology like symbolic interactionism, ethnomethodology, or Erving Goffman's "dramaturgy" have made an effort to flesh out a concept of human action, underscoring its creative, dramaturgical and interpretative features. These interpretative traditions define human actors as the makers and sustainers of social order and devote much attention to describing how local settings are produced by the 
ongoing creative agency of human participants. But this is a "little tradition" in the sociological project, in its approach and marginality analogous to social constructivist theories of technology. Like the latter (as Rammert rightly argues), there is a big gap between explanations stressing creative agency and local contingency and those aiming at the clarification of global structures as constraints on and resources for local agency. In this "big tradition", human agency is consistently schematised. Humans are treated more or less either as mechanical input-output devices (rational action theory), as bearers of sets of interests (class or otherwise) and "value dispositions", or as complex selfconstituting monads whose perceptions and motives in any given situation must be intuited by the analyst (i.e., Verstehen). All of these approaches impute arbitary dispositions to actors, making them available as narcissistic alter-egos of the sociologist. Hence, the rejection of nonhuman agency by classical sociology (and by Rammert in its wake) does not appear to be justified by the wish to preserve a deep and rich theory of human agency, but rather by its opposite, the fear of having to provide such a theory.

In a way this is an opportunity, rather than a liability. Pace Herman Hesse, we do not have to begin by first destroying a world. However, in order to exploit the opportunity, we have to avoid a certain idée fixe which has paralysed debates about admissible forms of agency. This is the notion that we have to define nonhuman agency as a sociological category. If our technology stories show anything at all about agency in a material world, it is that it is never either purely human or purely nonhuman, but intrinsically heterogeneous and hybrid. Agency is not, to be somewhat precipitous, rooted in the properties of entities-in-themselves, but rather in the properties of entities as elements of networks (or structures). And those networks/structures are invariably concatenations of both human and nonhuman actors. ${ }^{11}$

The idea of the actor-network encourages us to think in terms of distributed agency rather than the agency of discrete entities. In the S.E. Fireworks story, the bunkers and the explosives certainly acted, but they did not act alone, nor did they do so in isolation from human actors. The entire "hybrid collectif" of S.E. Fireworks is the agent of destruction here, not one or another human manager, operative or technical component. Arie Rip happens to live close to the site of the explosion. The concrete projectile which impacted in his back yard and pulverised several bricks there is no doubt an actor in respect to the previous structure of that bit of his back yard. However, it only became the actor it did by virtue of its former place in the hybrid socio-technical actor-network of S.E. Fireworks: a network, as it turned out, that consisted of an explosive mixture of unreliable humans and unreliable nonhumans implicated in complex agency-structure dynamics, i.e., in complex chains of mutual translation. 
It is the dynamics of such concatenations, i.e., Callon and Law's "hybrid collectifs", that have to be incorporated into the socio-logics of agency and structure, rather than nonhuman agency per se. This is of course a metaphysically daunting task, inasmuch as heterogeneous chains of agency and causality are implicated. It is a task that Rammert has neither attempted nor even defined as worthwhile - and I would say to the detriment of his otherwise admirable project. There are, however, promising leads. Marx's analysis of the machine is certainly one of them (MacKenzie 1984), with the tradition of labour-process theory in its wake (Noble 1984, Kern and Schuman 1970). More recently, Perrow's already cited work on "normal accidents" has given us fine-grained accounts of the behaviour of risk-ridden "hybrid collectifs" which could be extended to less accident-prone organisations and networks. Of course, actor-network theory has been the programmatic guiding light in regard to mixing metaphors (and actants). However, it is flawed by its preference for metaphysics in favour of history (i.e., sedimented structure) and by its polemical advocacy of the identity - rather than the sociological equivalence - of human and nonhuman agency. What we now need is an extension of Rammert's project which retains his commitment to the socio-logic of agency and structure, but which also incorporates the mixed ontology of the "hybrid collectif".

\section{Notes}

1 For an example of this mutual estrangement, see the recent exchange between Bruno Latour $\left(1999^{\mathrm{c}}\right)$ and David Bloor $\left(1999^{\mathrm{a}}, 1999^{\mathrm{b}}\right)$.

2 www.palm.com

3 g-2 coil-group minutes. February 12, 1987.

4 g-2 notes 007, minutes March 26, 1987, joint meeting.

5 g-2 notes 007, coil group meeting June 19, 1987.

6 Analysts from the actor-network school would assent to the tenor of this picture, although they would refer to processes of "stabilisation" and "irreversabilisation" rather than speak of a substantive structure or organisation. They would also, unlike sociologists, grant nonhumans their proper due in the actor-network.

7 Actor-network theory, set up as a technologically sensitive theoretical rival to sociology, also replicates this sociology of levels (Elias 1978) using concepts like "point-representation" and "macro-actor" (Callon and Latour 1981).

8 A major exception must be made for the tradition launched by Charles Perrow to which I will return below. See Perrow (1984) and Vaughan (1996).

9 In fact, in 2003, several new experiments were proposed (and will presumably be 
carried out) which utilise the generic capacity of the detector as a storage ring for muons. So even in this dedicated design there appears to be enough ambiguity to allow for different socio-technical practices-in-use.

10 See Boudon (1974) for an agonistic example of the struggle to define - and not to define - who or what the sociological actor is. The struggle is instructive because it is an explicit attempt to define the "rational kernel" of sociology on the basis of the synthesis of classical texts.

11 This position has a certain affinity with Barry Barnes's recent critique of the individualist bias in social theory (Barnes 2000), but with a difference. Barnes argues that the classical sociological tradition, including synthetic reformist theories like those of Talcott Parsons and Anthony Giddens, has been blighted by an undue stress on individualistic agency. This would seem to indicate for sociology an elaborated theory of human individuality, which ironically is lacking. Barnes concludes that the emphasis on human agency in recent social theory is a reaction to determinist sociologies. Agency boils down to the use of individual rationality to resist "irrational" societal "constraints". Human agents can be free because in the final analysis they are nobody's fool. Barnes argues that this individualistic approach, enshrined in Rational Action Theory, is misguided and that instead we should look for another kind of "collective agency" rooted in the essential sociality of human beings: “...the characteristic accomplishments of human beings are precisely the products of their lack of independence as responsible agents. Their cultures, institutions and forms of life; their inventions and innovations; their ability to generate and direct awesome concentrations of power; are all the result of their collective agency, which derives in turn from the the mutual susceptibility linked to their concern with face and status" (Barnes 2000, 143).

My argument that agency should not be situated in the properties of entities-inthemselves but in the networks they constitute with each other certainly resonates with this position in a formal sense, but I can see no self-evident way to map Barnes's conception of "mutual susceptibility" among humans onto the kinds of relationships prevailing between humans and nonhuman entities - let alone those among nonhuman entities themselves. If we succeed in theorising the agency of the "hybrid collectif" in a Barnesian vein, it will have to be by grafting the radically different logic of "natural law" (and its articulation with human agency) onto his humanist conception of mutual susceptibility "linked to concern with face and status". This would at the very least entail re-emphasising human rationality (as the capacity to understand and exploit behaviours subject to "natural law") as the basis of hybrid agency. As far as I can see, something like this would be the only route to incorporating nonhumans into Barnes's charmed circle of "collective agency". 